\title{
Influence of demographic factors on guidance needs of teacher trainees in Ghana
}

\author{
John Sedofia*, Department of Teacher Education, University of Ghana, P.O. Box LG 1181, Accra, Ghana \\ Eliot KosiKumassah, Department of Teacher Education, University of Ghana, P.O. Box LG 1181, Accra, Ghana
}

\section{Suggested Citation:}

Sedofia, J. \& Kumassah, E. K. (2020).Influence of demographic factors on guidance needs of teacher trainees in Ghana. Global Journal of Guidance and Counselling in Schools: Current Perspectives. 10(3), 110-119. https://doi.org/10.18844/gigc.v10i3.4859

Received from July 30, 2020; revised from October 20, 2020; accepted from December 12, 2020.

Selection and peer review under responsibility of Prof. Dr. Kobus Maree, University of Pretoria South Africa. ${ }^{\circledR} 2020$ Birlesik Dunya Yenilik Arastirma ve Yayincilik Merkezi. All rights reserved.

\begin{abstract}
The guidance needs of a particular student or group of students are likely to differ and evolve based on different variables. However, information on the influence of certain demographic variables on the guidance needs of teacher trainees at the Colleges of Education level in Ghana seems to be unavailable. Our purpose in this study was to investigate whether the guidance needs of teacher trainees in the Colleges of Education in Ghana varied based on their sex, age, marital status and the college in which they were enrolled. The study employed a survey research design in which data were collected with the help of a questionnaire from a total of 4012 nd-year teacher trainees ( 256 males and 145 females). Data were analysed using means, standard deviations, independent samples $t$-test and Kruskal-Wallis $\mathrm{H}$ test. The results showed that the guidance needs of teacher trainees in Colleges of Education in the Volta Region vary based on the trainees' sex, age, marital status and college. It was recommended that college counsellors should take into account the demographic variables of sex, age, marital status and college when designing and implementing guidance programmes in Colleges of Education.
\end{abstract}

Keywords: Counselling, guidance, guidance needs, guidance needs assessment, teacher trainees

* ADDRESS FOR CORRESPONDENCE: John Sedofia, Department of Teacher Education, University of Ghana, P.O. Box LG 1181, Accra, Ghana. E-mail address: jsedofia@ug.edu.gh 


\section{Introduction}

The effectiveness of any guidance program is contingent, in part, on knowing the guidance needs of those for whom the program is designed and tailoring guidance services to meeting those needs (Sedofia, Antwi-Danso \& Nyarko-Sampson, 2018). Effective school guidance and counselling services are based on the students' needs which are established through guidance needs assessment (Lunenburg, 2010), and counsellors can only help students when they know the guidance needs of the students (Zaidi, 2012).

Guidance needs assessment involves identifying the areas students require guidance and counselling. By assessing students' guidance and counselling needs, counsellors are better positioned to set goals and design guidance activities to meet those needs. Guidance needs assessment ensures that guidance services are designed to reflect the actual and most important needs of the students (Yakubu, Awabil \& Forde, 2017). Also, guidance needs assessment enhances the effective development of guidance programs (Gibson \& Mitchell, 2008).

Despite the important role guidance needs assessment plays in effective guidance service delivery, the literature appears to be scanty in the Ghanaian context and focuses heavily on secondary school students who differ from teacher trainees in many ways including age, marital status and experience (Brouzos, Vassilopoulos, Korfiati \& Baourda, 2015; Dogar, Azeem, Majoka, Mehmood \& Latif, 2011; Kumar \& Kumar, 2010; Sculli, 2011; Waititu \& Khamasi, 2010). Being a teacher trainee comes with some great personal, professional and financial costs, compared to being a secondary school student. Even within the college level, teacher trainees, particularly those in the Volta Region Colleges of Education, may present some unique needs.

At the tertiary education level where the Colleges of Education now fall, most of the studies on students' guidance needs appear to concentrate heavily on the university level (Bolu-Steve \& Ogungbade, 2016; Yakubu et al., 2017). Although Sedofia et al. (2018) discovered that the guidance needs of teacher trainees in Colleges of Education in the Volta Region guidance are academic, financial, social, personal and placement, the study fell short of showing whether such needs are influenced by the trainees' gender, age, marital status and the college they attend.

More importantly, some studies explored the relationship between students' guidance needs and a number of variables including grade level (Atik \& Yalcin, 2010), gender (Dada, Agbana \& Adetayo, 2010; Sculli, 2011), age (Brouzos et al., 2015) and religion (Bolu-Steve \& Ogungbade, 2016). However, findings on the relationship between students' guidance needs and gender, for instance, seem to be inconclusive. While some researchers found significant differences in students' guidance needs based on their gender (Guneri, Aydin \& Skovholt, 2003; Kenny, Aluede \& McEachern, 2009), some others found no such differences (Kumar \& Kumar, 2010; Yakubu et al., 2017). Also, these studies were carried out in settings and on populations that are completely different from those in the present study.

Even more serious is the absence of information on the influence of gender, age, marital status and college on the guidance needs of teacher trainees at the Colleges of Education in the Volta Region. This knowledge gap has serious implications for guidance and counselling at the College of Education level particularly in the Volta Region as it appears to account for the rollout of omnibus guidance and counselling programmes for teacher trainees regardless of demographic considerations. With this background and due to the fact that the needs of a particular student or group of students are likely to evolve along with the fast-changing world, the present study set out to ascertain whether or not the guidance needs of teacher trainees in the Volta Region of Ghana are influenced by demographic factors. To be able to achieve the above purpose, four null hypotheses were formulated and tested at 0.05 level of significance. 
1. There will be no statistically significant difference in the guidance needs of male and female teacher trainees.

2. There will be no statistically significant difference in the guidance needs of teacher trainees based on their marital status.

3. There will be no statistically significant difference in the guidance needs of different age groups of teacher trainees.

4. There will be no statistically significant difference in the guidance needs of teacher trainees of different colleges.

It is hoped that the findings will increase our knowledge on whether or not the guidance needs of teacher trainees are influenced by demographic variables in the study locale. The findings will also help counsellors in the colleges to design and implement guidance services more successfully.

\section{Methods}

\subsection{Research design}

The primary purpose of this study was to determine whether the guidance needs of teacher trainees in Colleges of Education in Ghana were based on their sex, age, marital status and the college in which they were enrolled. The study employed a survey research design. The researchers collected data from the participants on their demographics and guidance needs, summarised their responses with chi-square statistics and drew inferences about the population (Fraenkel, Wallen \& Hyun, 2019). The survey design was used mainly because it is less expensive and affords a rapid turnaround in data collection compared to other designs such as experiments (Creswell \& Creswell, 2018) and led to the testing of hypotheses on whether or not teacher trainees' guidance needs differ based on their gender, age, marital status and the college they attend.

\subsection{Sample and sampling procedures}

A total of 401 2nd-year teacher trainees (63.8\% male and 36.2\% female) drawn from three colleges were selected through a proportional stratified sampling technique. In stratified sampling, there are a number of homogeneous pre-existing subgroups in the population and the researchers want each of those subgroups to be represented in the final sample (Sarantakos, 2005). In this study, the preexisting subgroups of interest were based on college and sex.

First, the population was stratified based on college in order to get the number of trainees to be selected from each college. Another stratification was done to determine the number of male and female 2nd-year teacher trainees to be selected from each of the three colleges. After determining the strata and the number of subjects to be selected from each, the subjects were selected randomly. The proportional stratified sampling procedure increases the likelihood of representativeness, ensures that key characteristics of individuals in the population are included in the sample and is appropriate when various strata are different in size (Fraenkel et al., 2019).

\subsection{Research instrument}

A 27-item questionnaire, which was adapted from Sculli's (2011) 38-item needs assessment survey, was used to collect data for the present study. The questionnaire had two parts: A and B. Part A gathered demographic data (college, age, sex and marital status) while part B focused on the guidance needs of the trainees. A study on the specific guidance needs of teacher trainees has already been published (see Sedofia et al., 2018), hence that is not the focus of the present study. For purposes of this article, only data from part A of the questionnaire was used. This information was obtained in order to gain a better understanding of the teacher trainee population and to aid in determining whether or not guidance needs of teacher trainees differed based on those demographics. 
A Cronbach's alpha reliability coefficient of 0.732 was realized after piloting the instrument on 41 2nd-year teacher trainees ( 21 males and 20 females) of St. Francis College of Education, Hohoe. The purpose of the pilot test was to establish the psychometric properties of the instrument since it was adapted and the psychometrics of the original instrument were not explicitly stated. It was also to discover weaknesses, ambiguities, inadequacies and problems in the instrument so that those issues could be addressed before the actual data collection.

\subsection{Data analysis}

\section{Hypothesis 1:}

$\mathbf{H}_{0}$ : There will be no statistically significant difference in the guidance needs of male and female teacher trainees.

To be able to test the first hypothesis, the mean and standard deviation marks of teacher trainees' sex was computed. Then, an independent samples $t$-test was conducted to examine whether there was a significant difference in the guidance needs of male and female teacher trainees.

\section{Hypothesis 2:}

$\mathbf{H}_{0}$ : There will be nostatistically significant difference in the guidance needs of single and married teacher trainees.

Hypothesis two sought to establish whether there is a statistically significant difference in the guidance needs of teacher trainees who are single and those who are in a relationship or married. Means, standard deviations and independent samples $t$-test were used to test this hypothesis.

Hypothesis 3:

$\mathbf{H}_{\mathbf{0}}$ : There will be no statistically significant difference in the guidance needs of different age groups of teacher trainees.

The intent of hypothesis three was to establish whether or not differences exist in the guidance needs of different age groups of teacher trainees. The Kruskal-Wallis $\mathrm{H}$ test was used to test the hypothesis.

Hypothesis 4:

$\mathbf{H}_{0}$ : There will be no statistically significant difference in the guidance needs of teacher trainees of different colleges.

Hypothesis four sought to establish whether the guidance needs of teacher trainees differed across colleges. The Kruskal-Wallis $\mathrm{H}$ test was used to test the hypothesis.

The first and second hypotheses were analysed using independent sample $t$-test because the independent variables of hypothesis one and two are categorical and dichotomous while the dependent variables are quantitative or numerical. Kruskal-Wallis $\mathrm{H}$ test was used to analyse hypotheses 3 and 4, respectively. Although one-way analysis of variance (ANOVA) would have been good for testing these hypotheses, the data failed the normality test which is an assumption or a requirement for one to use the one-way ANOVA statistics. As a result, the Kruskal-Wallis $\mathrm{H}$ test, which is a non-parametric counterpart of ANOVA and good in testing for $k$ independent samples, was used instead.

\subsection{Ethical issues}

The ethical issues discussed in this study include: access and acceptance, informed consent, anonymity and confidentiality. 


\subsubsection{Access and acceptance}

The researchers personally went to the sampled colleges and sought permission from the institutional heads (principals) to carry out the study in their colleges. The permission was granted by the principal of each of the three colleges.

\subsubsection{Informed consent}

In the present study, informed consent was achieved by the researchers giving the participants information about the research topic and its purpose, the processes of the research, the handling of data and information about publication of the data. Participants were also told that their participation was voluntary and that they reserved the right to withdraw from the process at any point without any $\operatorname{cost}(s)$ to them.

\subsubsection{Anonymity and confidentiality}

The researchers addressed the issue of anonymity by asking the participants not to write their names on the questionnaire and assuring them that they would not be linked to the information they were going to provide. The issue of confidentiality was addressed by assuring the participants that the information they provided would be kept confidential and used only for research or academic purposes.

\section{Results}

Hypothesis 1: There will be no statistically significant difference in the guidance needs of male and female teacher trainees. Tables 1 and 2 present the findings on hypothesis 1.

Table 1. Mean difference of male and female teacher trainees' guidance needs

\begin{tabular}{llcc}
\hline Sex & $\boldsymbol{n}$ & Mean & Std deviation \\
\hline Male & 256 & 1.00 & 0.00 \\
Female & 145 & 2.20 & 0.969 \\
\hline
\end{tabular}

Table 1 describes the means and standard deviations of males and female teacher trainees. The data on Table 1 show that the mean value for male teacher trainees is 1.00 and that of females is 2.20. This information was subjected to a test of significance in order to examine the difference in the guidance needs of male and female teacher trainees. Table 2 presents the independent samples $t$-test results of the guidance needs of male and female teacher trainees.

Table 2. Independent t-test of male and female teacher trainees' guidance needs

\begin{tabular}{lccccc}
\hline & \multicolumn{2}{c}{ Levene's test for equality of variances } & \multicolumn{2}{c}{$\boldsymbol{t}$-test for equality of means } \\
& $\boldsymbol{F}$ & Sig. & $\boldsymbol{t}$ & $\mathrm{df}$ & Sig. (2-tailed) \\
\hline Equal variances assumed & 480.736 & 0.001 & -19.834 & 399 & 0.001 \\
Equal variances not assumed & & & -14.913 & 144.000 & 0.001 \\
\hline
\end{tabular}

Table 2 displays the result of an independent samples $t$-test which was conducted to examine whether there is a significant difference in the guidance needs of male and female teacher trainees. The test revealed a statistically significant difference between males and females $(t=-14.913$, $\mathrm{df}=144.000$ and $p=0.001<0.05$ ). Thus, female teacher trainees with $M=2.20, \mathrm{SD}=0.969$ showed significantly higher levels of guidance needs than their male counterparts with $M=1.00, \mathrm{SD}=0.00$. This means that male and female teacher trainees have different guidance needs. Hence, the null hypothesis is not accepted.

Hypothesis 2: There will be no statistically significant difference in the guidance needs of single and married teacher trainees. The results on hypothesis 2 are presented in Tables 3 and 4. 
Table 3. Mean difference of single and married teacher trainees

\begin{tabular}{lccc}
\hline \multicolumn{1}{c}{ Marital status } & $\boldsymbol{n}$ & Mean & Std deviation \\
\hline Single & 255 & 1.00 & 0.001 \\
Married/In a relationship & 146 & 2.38 & 0.911 \\
\hline
\end{tabular}

Table 3 gives the means and standard deviations of each group: singles and married/in-arelationship teacher trainees. Initially, there were three categories, namely, single, married and in a relationship. For purposes of the analysis, however, the three categories were collapsed into two: single and married/in a relationship. It can be seen from Table 3 that the mean value for teacher trainees who were single is 1.00 and the value for those who were married/in a relationship is 2.38 . An independent samples $t$-test was conducted to examine whether there was a significant difference in teacher trainees' guidance needs based on their marital status. The results are shown in Table 4.

Table 4. Independent t-test of single and married teacher trainees' guidance needs

\begin{tabular}{lccccc}
\hline & \multicolumn{2}{c}{ Levene's test for equality of variances } & \multicolumn{3}{c}{$\boldsymbol{t}$-test for equality of means } \\
& $\boldsymbol{F}$ & Sig. & $\boldsymbol{t}$ & df & Sig. (2-tailed) \\
\hline Equal variances assumed & 663.569 & 0.001 & -25.178 & 399 & 0.001 \\
Equal variances not assumed & & & -17.018 & 125.000 & 0.001 \\
\hline
\end{tabular}

Table 4 displays the independent samples t-test results of teacher trainees' guidance needs and their marital status. The test revealed a statistically significant difference between the two groups $(t=-17.018, \mathrm{df}=125.000$ and $p=0.001<0.05)$. That is, single teacher trainees had $M=1.00$, $\mathrm{SD}=0.001$, while married/in a relationship teacher trainees had $M=2.38, \mathrm{SD}=0.911$. The mean difference shows that teacher trainees who were married or in a relationship reported a greater need for guidance than their colleagues who were single. Clearly, the guidance needs of single teacher trainees are different from those of their counterparts who are married or in a relationship. Since there are differences between the categories, the null hypothesis is not accepted.

Hypothesis 3: There will be no statistically significant difference in the guidance needs of different age groups of teacher trainees. The results for this hypothesis are found in Table 5.

Table 5. Mean ranks of teacher trainees' guidance needs and their ages

\begin{tabular}{ccc}
\hline Age & $\boldsymbol{n}$ & Mean rank \\
\hline $15-19$ & 2 & 147.00 \\
$20-24$ & 344 & 174.27 \\
$25-29$ & 50 & 367.96 \\
$30-34$ & 2 & 392.00 \\
$35-39$ & 3 & 392.00 \\
Total & 401 \\
*Chi square $(224.547,4)=0.001<0.05$.
\end{tabular}

Table 5 displays the results of the Kruskal-Wallis $\mathrm{H}$ test of trainees' guidance needs and their ages. The ages were put into five groups: 15-19, 20-24, 25-29, 30-34 and 35-39. The test shows that there is a statistically significant difference in guidance needs of the different age groups, $\chi^{2}(4)=224.547$, $p=0.001$, with a mean rank guidance needs of 147.00 for ages between 15 and 19, 174.27 for 20-24, 367.96 for $25-29,392.00$ for $30-34$ and 392.00 for 35-39. It means that trainees of different age groups have different guidance needs. The null hypothesis is therefore not accepted.

Hypothesis 4: There will be no statistically significant difference in the guidance needs of teacher trainees of different colleges. Table 6 shows the results on hypothesis 4 . 
Table 6. Teacher trainees' guidance needs and the colleges they attend

\begin{tabular}{|c|c|c|}
\hline Colleges & $n$ & Mean rank \\
\hline AKATSICO & 216 & 147.00 \\
\hline DATCO & 103 & 191.68 \\
\hline AMECO & 82 & 354.95 \\
\hline Total & 401 & \\
\hline
\end{tabular}

Tables 6 shows the results of the Kruskal-Wallis $\mathrm{H}$ test of teacher trainees' guidance needs and the colleges they attend. The test reveals that there is a statistically significant difference in the guidance needs of trainees across colleges, $\chi^{2}(2)=317.237, \mathbf{p}=0.001$, with a mean rank guidance need of 147.00 for AKATSICO, 191.68 for DATCO and 354.95 for AMECO. This result means that the guidance needs of teacher trainees differ from college to college. The null hypothesis is therefore not accepted.

\section{Discussion}

\subsection{Guidance needs and sex}

This study discovered that there are differences in the guidance needs of male and female teacher trainees. The results on Tables 1 and 2 indicate that female teacher trainees $(M=2.20, S D=0.969)$ showed significantly higher levels of guidance needs than their male counterparts $(M=1.00$, $\mathrm{SD}=0.00$ ). This finding is supported by a number of studies which reported gender differences in students' guidance needs (Couture, 2002; Dada et al., 2010; Kennyet al., 2009; Sculli, 2011). Aluede, Imhonde and Eguavoen (2006) revealed that female students had higher needs in the financial area than male students. Atik and Yalcin (2010) equally found significant differences in the guidance needs of male and female students. Bolu-Steve and Ogungbade (2016), however, found no significant difference in the guidance needs of students on the basis of their gender.

The guidance needs of teacher trainees in the Volta Region are academics (study habit, how to further their studies, time management and test anxiety), finance (how to fund their education and how to handle or use money), social (intimate or boy/girlfriend relationship, interpersonal relationship), personal (knowing oneself, problem solving, self-control) and placement (the selection of elective courses, postings, and joining other professions) (Sedofia et al., 2018). In the present study, it is not precisely clear why no difference was found in the guidance needs of male and female students. There is no doubt, however, that physiological, physical and emotional differences exist between men and women. These fundamental differences in the physio-psychological make-up of men and women are bound to bring differences in their needs in general and their guidance needs in particular.

\subsection{Guidance needs and marital status}

The study also found that guidance needs differ based on marital status. Teacher trainees who were married or in a relationship reported a greater need for guidance than their colleagues who were single (see Tables 3 and 4). This result is not surprising. Teacher trainees who are married or in a relationship are actually servants of two masters: their academic work on one hand and their relationships on the other. Failure to serve the masters well would result in the loss of one or both. The quest to satisfy both masters well puts a toll on them academically, financially and socially. This situation can pose a great challenge to individuals and make their need for guidance increase and varied.

Indeed, students in colleges are young adults who feel more concerned about their future: getting a job, making a home or continuing higher education (Amadi, 2001), and many of them may have some issues that are economic, personal-social or educational for which they need the help of a counsellor 
to handle (Sedofia, 2011). As has been found in the literature, there is a relationship between marital status and students' guidance needs. Married students were found to have more financial and relationship counselling needs than their single/non-married counterparts (Aluede et al., 2006).

Dada et al. (2010), however, found that there were no significant differences in respondents' counselling needs and their marital status. Clearly, this finding is in sharp contrast to the result of the present study and that of Aluede et al. (2006) on marital status and guidance need. In view of this, further research is required to establish whether there is a significant difference in guidance needs based on one's marital status.

\subsection{Guidance needs and age}

It was further discovered that there are age differences in teacher trainees' guidance needs (Table 5). A number of studies found differences in students' guidance and counselling needs and their ages, in line with the present study's findings. Sculli (2011) reported differences among grade-level needs. Guneri et al. (2003) also found significant differences in the counselling needs of students with respect to age. Again, Couture (2002) reported that younger students were more concerned with relationships and social problems than older students. That study further found that although both younger and older students placed a high priority on life planning, older students placed greater emphasis on futureoriented concerns related to careers, academics and self-management.

It is to be expected that students of different ages would report different needs for guidance. Particularly as people grow older, they come face-to-face with issues such as entering and maintaining a career, entering and maintaining intimate relationships, working and getting money to meet one's financial needs and so on. These issues are likely to make an older person's need for guidance different from that of a younger person. People at different stages of their lives will be motivated by different things (Martin, 2005).

On the contrary, Dada et al. (2010) did not find any significant differences in students' counselling needs based on their age and year of study. Thus, the present study's finding that differences exist in the guidance needs of different age groups of teacher trainees does not support that of Dada et al. (2010).

\subsection{Guidance needs and college}

Finally, the study found that the guidance needs of teacher trainees differ from college to college (Table 6). The present study's discovery that teacher trainees' guidance needs differ from one college to the other is supported by that of Kenny et al. (2009). They compared the needs of graduate counselling students in the United States and Nigeria and found that overall there was a significant difference in all areas of concern for students, with Nigerian students obtaining higher subscale scores than U.S. students, in all but one domain (financial). The U.S. students reported that their five highest concerns were time management, finance, getting a job, debt levels and test anxiety. The Nigerian students on the other hand stated that their major concerns were managing time, improving memory, concentrating on studies, getting better grades and completing assignments on time.

Guneri et al. (2003), however, found no significant differences in students' counselling needs based on college. This clearly shows that the current study's finding on guidance needs and college contradicts that of Guneri et al. (2003).

However, there is no doubt that several factors bring about differences in educational institutions. Some institutions are located in the cities but others are found in the rural areas. In terms of resources, both human and material, some of the institutions can be described as wellendowed while others can be said not to be very well-endowed. These factors, among others, can no doubt influence the guidance needs of students. 


\section{Implications for practice}

From the present study, it emerged that the teacher trainees who are married or are in a relationship have a higher need for guidance. This implies that college counsellors should put in place the requisite measures to meet the needs of that category of trainees. Similarly, guidance needs differ based on sex. Therefore, college counsellors should design and implement guidance activities to meet the needs of both sexes.

Also, there are trainees of different ages in the Colleges of Education. Since the present study found that teacher trainees of different ages have different guidance needs, it implies that counsellors at the various Colleges of Education should take into account the age differences that exist in trainees. Such differences in the age of trainees should lead to the design and delivery of age-specific guidance services. This will go a long way to make guidance meet the needs of every trainee no matter their age.

Finally, the present study discovered that guidance needs are not the same for trainees in all the Colleges. In view of the fact that there are college-specific guidance needs, guidance practitioners need to tailor guidance services towards meeting those needs for students.

\section{Conclusions and recommendations}

From the findings of this study, it can be concluded that the guidance needs of teacher trainees in the Volta Region of Ghana are influenced by demographic variables. What this means is that trainees of different sexes, ages, marital statuses and college have different guidance needs. This conclusion is based on the fact that all the null hypotheses for the present study were not accepted. Since the current study was limited to only 2nd-year teacher trainees and only Colleges of Education in the Volta Region, future research should involve all year groups of trainees and be extended to other regions in Ghana.

\section{Limitations}

In this study, only 2 nd-year teacher trainees were involved because at the time of collecting data, 1st-year trainees had not done at least one academic year to qualify to participate in the study. On the other hand, 3rd-year trainees were on internship in communities outside the colleges at the time. As a result, only 2 nd-year teacher trainees were involved in the study. Had all the 3-years groups of trainees been involved in the study, the data and the results that emerged from them may have been different from what we have now. The conclusions drawn from this study therefore cannot apply to every teacher trainee in the Colleges of Education in the Volta Region.

\section{Acknowledgements}

The authors acknowledge all the 2nd-year teacher trainees who participated in the study. They are also grateful to the Principals for allowing us to conduct the study in their colleges.

\section{Declaration of Interest Statement}

The authors have no conflict of interest as far as this paper is concerned.

\section{References}

Aluede, O., Imhonde, H. \& Eguavoen, A. (2006). Academic, career and personal needs of Nigerian university students. Journal of Instructional Psychology, 33(1), 50-58.

Amadi, A. V. (2001). Meaning and scope of guidance. Owerri, Nigeria: International Universities Press. 
Atik, G. \& Yalcin, I. (2010). Counselling needs of educational sciences students at the Ankara University. Procedia Social and Behavioural Sciences, 2(2010), 1520-1526.

Awabil, G. (2007). Guidance needs of senior secondary school students in the Bulsa and Kassena Nankana District of the Upper East Region. Journal of Counselling, Education and Psychology, 1(1), 86-101.

Bolu-Steve, F. N. \& Ogungbade, O. K. (2016). Factors that determine use of the counselling centre by students of a Nigerian institution of higher learning. Zimbabwe Journal of Educational Research, 28(1), 104-122.

Brouzos, A., Vassilopoulos, S., Korfiati, A. \& Baourda, V. (2015). Secondary school students' perceptions of their counselling needs in an era of global financial crisis: an exploratory study in Greece. International Journal for the Advancement of Counselling, 37(2), 168-178.

Couture, S. (2002). Addressing student needs throughout development. Canadian Journal of Counselling, 36(1), 38-48.

Creswell, J. W. \& Creswell, J. D. (2018). Research design: qualitative, quantitative, and mixed methods approaches (5th ed.). Los Angeles, CA: SAGE Publications, Inc.

Dada, M. F., Agbana, E. O. \& Adetayo, T. (2010). Counselling needs of sandwich students of University of AdoEkiti College of Education, Oro Campus, Kwara State, Nigeria. The Nigerian Journal of Guidance and Counselling, 15(1), 35-50.

Dogar, A. H., Azeem, M., Majoka, M. I., Mehmood, A. \& Latif, S. (2011). Need assessment of students' guidance and counselling. British Journal of Arts and Social Sciences, 1(2), 108-124.

Fraenkel, J. R., Wallen, N. E. \& Hyun. H. H. (2019). How to design and evaluate research in education. New York, NY: McGraw Hill Education.

Gibson, R. L. \& Mitchell, M. H. (2008). Introduction to counselling and guidance (7th ed.).Upper Saddle River, NJ: Prentice-Hall.

Gravetter, F. J. \& Forzano, L. A. B. (2009). Research methods for the behavioural sciences (3rd ed.). Belmont. MA: Cengage Learning.

Guneri, O.Y., Aydin, G. \& Skovholt, T. (2003). Counselling needs of students and evaluation of counselling services at a large urban university in Turkey. International Journal for the Advancement of Counselling, 25(1), 53-63.

Kenny, M. C., Aluede, O. \& McEachern, A. (2009). A comparison of counselling students' needs in the United States and Nigeria. Australian Journal of Guidance andCounselling, 19(1), 41-55.

Kumar, A. \& Kumar, R. (2010). Guidance needs of adolescents studying in Jawahar Navodaya Vidyalayas in Himachal Pradesh. International Journal of Education and Allied Sciences, 2(2), 59-64.

Lunenburg, F. C. (2010). School guidance and counselling services.Schooling, 1(1), 1-9.

Martin, J. (2005). Organizational behaviour and management (3rd ed.). Andover, UK: Cengage Learning EMEA.

Sarantakos, S. (2005). Social research (3rd ed.). Houndmils, UK: Macmillan Press Ltd.

Sculli, N. (2011). Assessing the counselling needs of high school students: the role of needs assessment in Comprehensive School Counselling Programs (CSCPS) and the ASCA national model (Unpublished master's thesis). State University of New York College at Brockport, Brockport NY.

Sedofia, J. (2011). An evaluation of the guidance program in the colleges of education in the Volta Region of Ghana (Unpublished master's thesis). University of Cape Coast, Cape Coast, Ghana.

Sedofia, J. (2016). Guidance needs and services among teacher trainees of Colleges of Education in Volta region (Unpublished doctoral thesis). University of Education, Winneba, Ghana.

Sedofia, J., Antwi-Danso, S. \& Nyarko-Sampson, E. (2018). Guidance needs of teacher trainees in selected Colleges of Education in the Volta region, Ghana. British Journal of Education, 6(7), 95-107.

Waititu, L. \& Khamasi, J. W. (2010). Situation analysis of guidance and counselling in secondary schools in Kenya: can municipality schools cope. Kenya Association of Educational Administration and Management (KAEAM), 33-41.

Yakubu, A. K., Awabil, G. \& Forde, L. N. D. (2017). Counselling needs of students in the University of Health and Allied Sciences in Ghana. Journal of Educational Development and Practice (JED-P), 1(1), 1-13.

Zaidi, S. F. (2012). Construction of guidance need inventory at graduate level. International Multidisciplinary e-Journal, 1(V), 79-84. 